\title{
SPECTROSCOPY IN INDUSTRY
}

Spectrographic Analysis in Great Britain Edited by A. C. Candler. Pp. 80. (London: Adam Hilger, Ltd., 1939.) $7 s$. $6 d$. net.

MODERN spectrographs suitable for industrial 1 work originated in Great Britain nearly thirty years ago, and their application to industry has been continuously increasing for three main reasons. First, for purely routine control, the spectrographic method is often much more rapid than a purely chemical one and, moreover, may require fewer workers. Secondly, chemical analysis may be less reliable when the estimation of mere traces of certain elements is involved. Finally, only small quantities of material are required for spectrographic analysis.

The monograph under consideration comprises twenty-eight articles describing the application of spectroscopic methods to a wide range of subjects, including analysis of alloys, detection of metallic contamination of beers, agricultural problems, archæology, and last, but by no means least, to forensic science. All the articles are brief.
The spectrograph, for example, has proved helpful in tracking down the causes of obscure diseases of crops and stock. Thus teart, to which cattle in certain areas are subject, is found to be associated with an increased molybdenum content in the herbage. In view of the minute traces of molybdenum involved, a long time would undoubtedly have elapsed before this discovery could have been made, had chemical methods alone been available.

The concluding article, which deals with forensic science, suggests numerous ways in which the spectroscope can assist in tracking the criminal. Thus counterfeit coins may be compared with dust from the suspect's pockets; a fragment of glass from the turn-up of a suspect's trousers may be compared with the glass of a window broken in a smash and grab raid.

The monograph may be recommended to all interested in the application of spectroscopy to almost every walk of life.

\section{J. Newton Friend.}

\section{THE FACTORS OF THE MIND}

The Factorial Analysis of Human Ability

By Prof. Godfrey H. Thomson. Pp. $x v+326$. (London: University of London Press, Ltd., 1939.) 16s. net.

$\mathrm{M}^{\circ}$ OST psychologists have assumed that all mental activities are reducible to a small number of independent 'factors', such as intelligence, emotionality, verbal capacity, manual capacity, introversion or its opposite, and the like. Prof. Thomson's book is concerned, not so much with discovering what these factors may be, but rather with a critical examination of the mathematical procedure by which, it has been claimed, their existence may be established.

The older 'faculty school' simply postulated such elementary capacities as they were required; the newer school of statistical psychology supposes that they can be deduced mathematically by analysing correlations between test-performances or estimates of character. Various methods have been devised for this purpose--all loosely covered by the broad term 'factor analysis'. Of these the earliest was Prof. C. Spearman's well-known attempt to demonstrate that all mental processes involve a single intellectual factor, identifiable with 'general intelligence'. His formulæ assumed that two factors only were sufficient to account for every test performance. Later work in Great Britain, particularly in the field of educational testing, indicated that more specialized factors (verbal capacity, arithmetical capacity, etc.) appeared to enter into different tests, in addition to the 'specific factor' peculiar to each one and the 'general factor' common to all. The notion of multiple factors, as a substitute for that of dual factors, has since found strong support in America; and recent workers have endeavoured in various ways to generalize the simpler theorems of the two-factor hypothesis to meet these wider needs.

In the book under notice, Prof. Thomson brings together into a single clear and systematic exposition all the chief factorial methods that have hitherto been put forward. He explains their mathematical derivation in an elementary way for the student of psychology, and briefly compares their merits and their disadvantages. $\mathrm{He}$ also incorporates a summary of his own very valuable contributions, including more particularly a revised version of the sampling theory which he 